\title{
Influence of joint slippage on the cyclic response of steel frames
}

\author{
P. Nogueiro ${ }^{*}$ L. Simões da Silva ${ }^{\curlywedge}$, R. Bento ${ }^{+}$ \\ *Department of Civil Engineering, \\ IPB-Instituto Politécnico de Bragança, Portugal \\ ` Department of Civil Engineering, \\ University of Coimbra, Portugal \\ ${ }^{+}$Department of Civil Engineering, \\ IST-Instituto Superior Técnico, Lisboa, Portugal
}

\begin{abstract}
Steel joints subjected to cyclic loading whereby the amplitude of the applied forces exceeds the yield strain of one or more of the relevant connection components usually exhibit degradation of its moment-rotation response that eventually leads to failure of the joint. Depending on the actual design of end-plate beam-to-column steel joints, the cyclic response may present slippage.

It is the purpose of the present paper to (i) discuss the various hysteretic models available to model steel joints under cyclic loading; (ii) describe a numerical implementation of two such models, with and without slippage, and (iii) compare the cyclic response of two distinct joints (with and without slippage), and (iv) based on a selected test case, assess the influence of slippage on global behaviour of the structure.
\end{abstract}

Keywords: Structural Engineering, Semi-Rigid Behaviour, Steel Structures, Component Method, Component Behaviour, Beam-to-column Joints, Cyclic Behaviour, Seismic Behaviour.

\section{Introduction}

Steel joints subjected to cyclic loading whereby the amplitude of the applied forces exceeds the yield strain, of one or more of the relevant connection components, usually exhibit degradation of its moment-rotation response that eventually leads to failure of the joint. This phenomenon has been the object of extensive experimental investigations in what is commonly called "low-cycle fatigue”, the most recent impetus following the Kobe and Northridge earthquakes. As a result of these two earthquakes, unexpected failures of steel joints were observed, reflecting the poor behaviour of some less ductile components that could not dissipate the high frequency content of those two seismic events. 
Concentrating on end-plate beam-to-column bolted joints, and depending on its actual design, the cyclic response may present slippage. Examples of typical cyclic moment-rotation curves are shown in Figure 1.
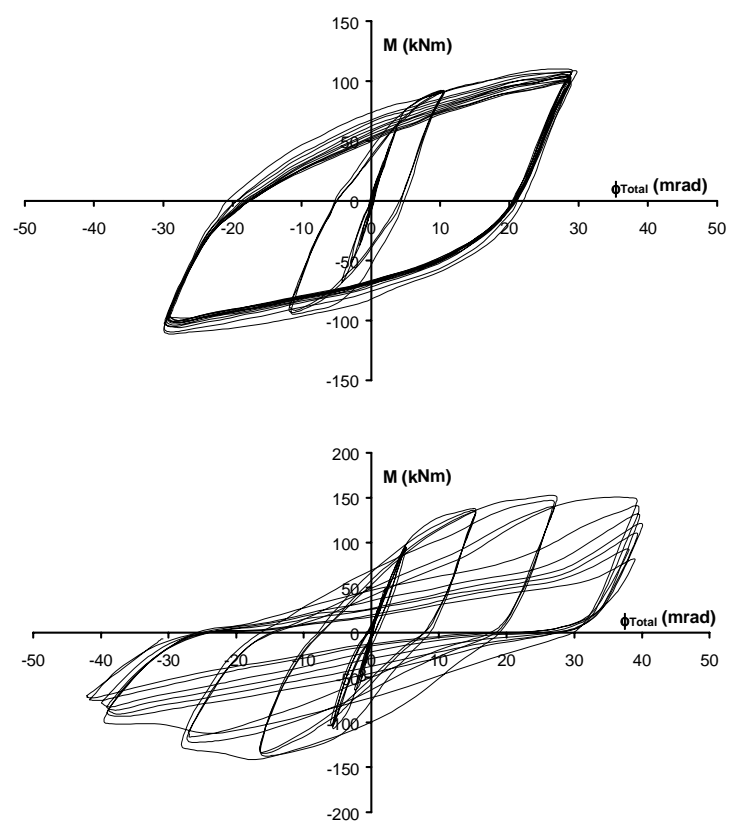

Figure 1: Typical cyclic moment-rotation curves in steel joints: a) without slippage; b) with slippage.

In order to explore the influence of slippage on the behaviour of steel frames subjected to cyclic loading, a representative steel structure, typical of a low-rise office building, was selected. More specifically, it is the purpose of the present paper to (i) discuss the various hysteretic models available to model steel joints under cyclic loading; (ii) describe a numerical implementation of two such models, with and without slippage, and (iii) compare the cyclic response of two distinct joints (with and without slippage), and (iv) based on a selected test case, assess the influence of slippage on global behaviour of the structure.

\section{Hysteretic models}

\subsection{Theory}

\subsubsection{Richard-Abbott model}

The Richard-Abbott model is based on a formula developed in 1975 [1] to reproduce the elastic-plastic behaviour of several materials and was initially used to simulate the static monotonic response of joints and later applied to cyclic situations [2]. According to this model, the loading branch of the moment-rotation curve of a joint is described by equation (1). 


$$
M=\frac{\left(k-k_{p}\right) \cdot \phi}{\left[1+\left|\frac{\left(k-k_{p}\right) \cdot \phi}{M_{0}}\right|^{N}\right]^{1 / N}}+k_{p} \cdot \phi
$$

where $M$ denotes the bending moment and $\phi$ the joint rotation. Parameters $k, k_{p}$ and $M_{0}$ are defined in Figure 2a, while $N$ may be related with these parameters by the following equation:

$$
N=\frac{-\ln 2}{\ln \left(\frac{M_{1}}{M_{0}}-\frac{k_{p}}{k-k_{p}}\right)}
$$
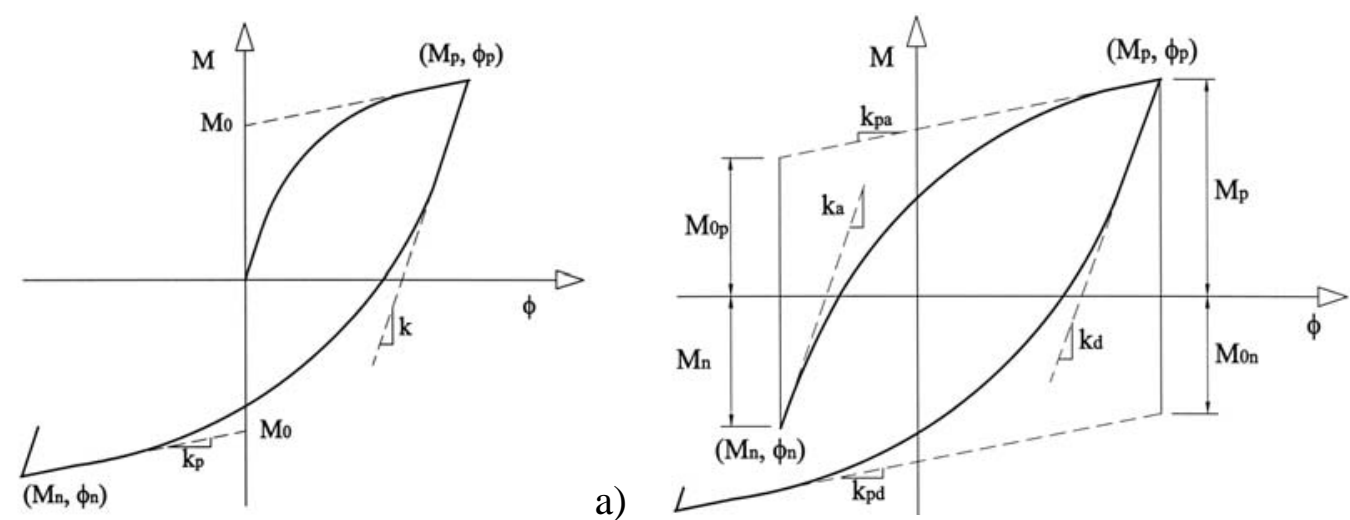

b)

Figure 2: Richard-Abbott model, adapted to deal with different behaviour under positive and negative bending.

In asymmetrical joints with respect to the centroidal axis, as in the case of composite joints, the model must be modified in accordance with Figure $2 b$ [3]. The loading curve for a generic branch is now given by the equation (3).

$$
M=M_{n}-\frac{\left(k_{a}-k_{p a}\right) \cdot\left(\phi_{n}-\phi\right)}{\left[1+\left|\frac{\left(k_{a}-k_{p a}\right) \cdot\left(\phi_{n}-\phi\right)}{M_{0 a}}\right|^{N}\right]^{1 / N}}-k_{p a} \cdot\left(\phi_{n}-\phi\right)
$$

where $M_{0 a}=M_{n}+M_{0 p}$. The unloading curve is obtained in the same way, replacing $\left(M_{n}, \phi_{n}\right)$ by $\left(M_{p}, \phi_{p}\right)$ and the parameters $M_{0 a}, k_{a}$ and $k_{p a}$ by the corresponding values evaluated at unloading, $M_{0 d}, k_{d}$ and $k_{p d}$. 
In general, whenever a joint is subjected to successive loading cycles in plastic regime, parameters $k, k_{p}, M_{0}$ and $N$ (either for the loading or unloading branches) does not remain constant. In particular, stiffness $k$ and moment $M_{0}$ exhibit a tendency to reduce, corresponding to the degradation of the mechanical properties of the joint.

\subsubsection{Modified Mazzolani model}

The model proposed by Mazzolani [2,4] (De Martino et al., 1984; Mazzolani, 1988), based on the Ramberg-Osgood model, allows the mathematical simulation of hysteretic behaviour with slippage, where the cycles have the shape shown in Figure 3. As originally proposed, each complete cycle was divided in four branches (I, II, III and IV), the definition of branches I and II being similar to branches III and IV. However, in unsymmetrical joints, all parameters must be defined separately for the positive (branches I and II) and negative (branches III and IV) zones.

Given that, in joints with slippage, the corresponding branch may start in the unloading zone, thus preventing the application of the model, a modified version was proposed in Simões et al [3]. It consists of the definition of each cycle with two single branches, ascending and descending, as described in Figure 3, thus eliminating the limitation of slippage not being able to occur in the unloading branch, and is described below in detail.

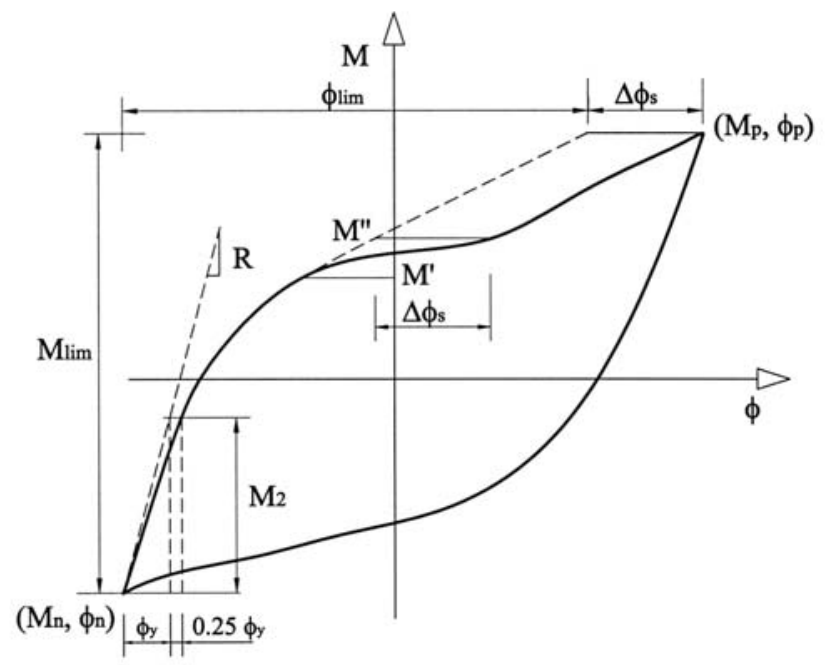

Figure 3: Definition of complete cycle according to the Mazzolani model.

The mathematical description of the ascending branch I ( $\left.M_{n} \leq M \leq M_{p}\right)$ is given by equations $(4 \mathrm{a})$ to $(4 \mathrm{c})$. The initial rotation $\left(\phi_{\mathrm{n}}\right)$ and initial stiffness $(\mathrm{R})$ are evaluated at point $\left(\mathrm{M}_{\mathrm{n}}, \phi_{\mathrm{n}}\right)$ :

$$
\phi=\phi_{n}+\frac{M-M_{n}}{R}+c_{1} \cdot\left(\frac{M-M_{n}}{M_{2}}\right)^{c_{2}} \quad \text { if } \quad M_{n} \leq M \leq M^{\prime}
$$




$$
\begin{aligned}
& \phi=\phi_{n}+\frac{M-M_{n}}{R}+c_{1} \cdot\left(\frac{M-M_{n}}{M_{2}}\right)^{c_{2}}+\frac{\Delta \phi_{s}}{2}+\left(\frac{\Delta \phi_{s}}{2}-K_{m}\right) \cdot \rho \cdot|\rho|^{s-1}+K_{m} \cdot \rho \\
& \phi=\phi_{n}+\frac{M-M_{n}}{R}+c_{1} \cdot\left(\frac{M-M_{n}}{M_{2}}\right)^{c_{2}}+\Delta \phi_{s} \quad \text { if } \quad M^{\prime \prime} \leq M \leq M^{\prime \prime}
\end{aligned}
$$

Moment $\mathrm{M}_{2}$ is used to constrain the curve to an intermediate point, defined as a rotation of the order of 1.25 the elastic rotation, so that this point lies outside the slippage branch. Parameters $c_{1}$ and $c_{2}$ are obtained from equations (5) and (6).

$$
\begin{gathered}
c_{1}=0.25 \cdot \phi_{y}=0.25 \cdot \frac{M_{2}}{R} \\
c_{2}=\frac{\ln \left[\left(\phi_{\lim }-\frac{M_{\lim }}{R}\right) / c_{1}\right]}{\ln \left(M_{\lim } / M_{2}\right)}
\end{gathered}
$$

where $\quad M_{\lim }=\left|M_{n}\right|+\left|M_{p}\right| \quad$ and $\quad \phi_{\lim }=\left|\phi_{n}\right|+\left|\phi_{p}\right|-\Delta \phi_{s}$.

The stiffness at the start of each cycle (R) is obtained as a function of the accumulated energy of the previous cycle $(\Omega)$, according to equation (7), as shown in Fig. 4a.

$$
R=R_{0} \cdot\left[1-\frac{\Delta R}{R_{0}} \cdot\left(\frac{\Omega}{\Omega_{\text {máx }}}\right)^{c}\right]
$$

where:

$R_{0} \quad$ - Tangent in the beginning of the first cycle, obtained from the static monotonic moment-rotation results;

$\Delta R \quad$ - Tangent variation, between the first and last cycle before collapse;

$\Omega \quad$ - Accumulated energy at the end of the previous cycle;

$\Omega_{\text {máx }}$ - Accumulated energy at collapse;

c $\quad$ - Parameter defined according to Fig. 4.

Equation (4b) results from adding the slippage effect between $M$ ' and $M$ ' to equation (4a). The second part of equation (4b) is defined in terms of the slippage $\Delta \phi_{s}$ and the parameters $\rho, s$ and $K_{m}$. The parameter $\rho$ is related to the bending moments $M, M$ ' and $M$ ' ' through equation (8). 
$\rho=\frac{2 \cdot M-M^{\prime}-M^{\prime \prime}}{M^{\prime \prime}-M^{\prime}}$

$\left(-1<\rho<1\right.$ for $\left.M^{\prime}<M<M^{\prime \prime}\right)$

Parameters $K_{m}$ and $s$ ensure continuity at points $M=M^{\prime}$ and $M=M^{\prime \prime}$ (Fig. $\left.4 \mathrm{~b}\right)$.

$S=\frac{K_{m}}{K_{m}-\Delta \phi_{s} / 2} \quad$ with $K_{m}>\Delta \phi_{s} / 2$

Assuming that slippage $\Delta \phi_{s}$ varies from cycle to cycle, it could be related to the accumulated energy $\Omega$ until the previous cycle, through equation:

$\Delta \phi_{s}=\Delta \phi_{s, \text { min }}+\left(\Delta \phi_{s, \text { máx }}-\Delta \phi_{s, \text { min }}\right) \cdot\left(\frac{\Omega}{\Omega_{\text {máx }}}\right)^{g}$

where:

$\Delta \phi_{s, \min } \quad$ - Slippage in the first cycle;

$\Delta \phi_{s, m a ́ x}$ - Slippage in the last cycle before failure;

$g \quad$ - Calibration parameter.

Finally equation (4c) expresses the hysteretic behaviour after slippage, obtained through equation (4a), by means of a translation corresponding to slippage $\Delta \phi_{s}$.

Starting from the positive extremum of the previous half-cycle, the descending branch is defined in a similar fashion.

To reproduce the strength degradation in the current model, a degradation curve is proposed for $\mathrm{M}_{\mathrm{lim}}$ similar to the one considered for stiffness (R). Starting from an initial value, the current value for a given cycle is given by:

$M_{\lim }=M_{\lim 0} \cdot\left[1-\frac{\Delta M_{\lim }}{M_{\lim 0}} \cdot\left(\frac{\Omega}{\Omega_{\text {máx }}}\right)^{p}\right]$

where:

$M_{\text {lim0 }}$ - Initial $M_{\text {lim }}$, obtained from the static monotonic moment-rotation results;

$\Delta M_{\text {lim }}$ - Difference between $M_{\lim }$ evaluated at the first and last cycle before collapse;

$\Omega \quad$ - Accumulated energy at the end of the previous cycle;

$\Omega_{\text {máx }} \quad$ - Accumulated energy at collapse;

$p \quad$ - Parameter defined according to Figure 4c. 
In contrast with stiffness, $\mathrm{M}_{\mathrm{lim}}$ does not decrease for cycles with amplitudes little greater than the elastic amplitude; on the contrary, from the elastic amplitude $(\Omega=$ 0 ) and up to a certain value, an increase of $\mathrm{M}_{\mathrm{lim}}$ is noted. Consequently, equation (11) should only be used for cycles of amplitude equal or larger than the maximum attained moment. For steel and composite joints, this corresponds to 4 times the elastic amplitude, $\mathrm{M}_{\text {lim }}$ being obtained directly from the static monotonic or cyclic envelope of the moment-rotation curve for smaller amplitudes.

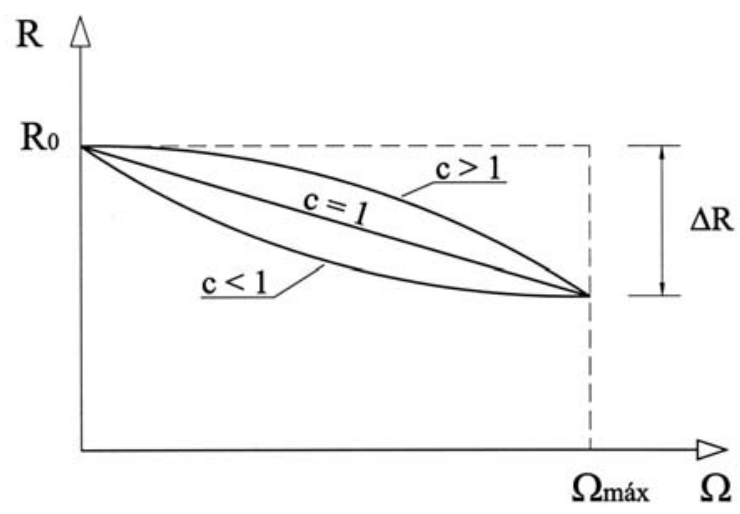

Figure 4a: Tangent to the $M-\phi$ curve as a function of the accumulated energy

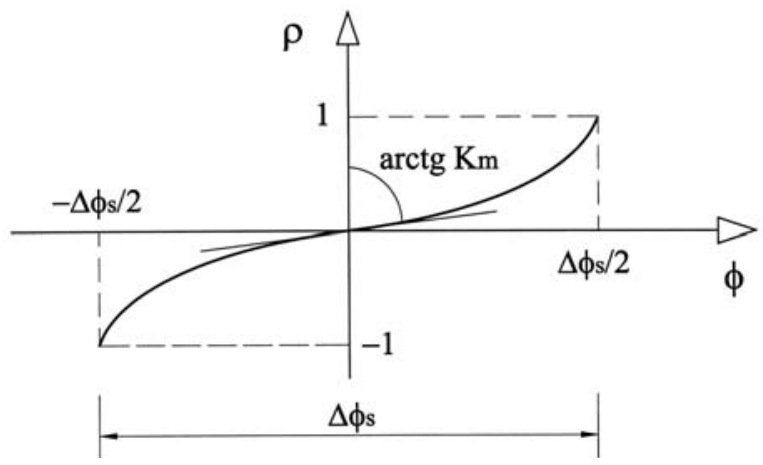

Figure 4b: Part of the $M-\phi$ curve where slippage occurs.

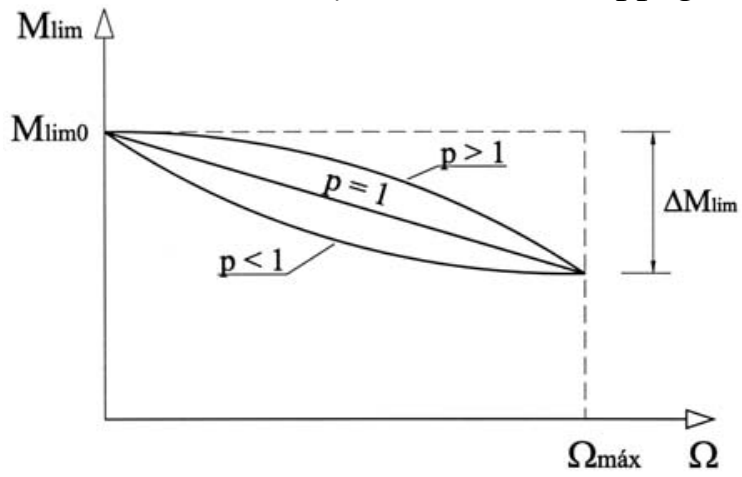

Figure 4c: Relation between $M_{\text {lim }}$ and the accumulated energy (a) Internal node with steel column, (b) External node with composite column. 


\subsection{Numerical implementation and experimental calibration}

The two cyclic models described above were numerically implemented using the Delphi programming environment and Object Pascal [5]. For the Richard-Abbott model, the controlling variable is rotation $\phi$, while for the modified Mazzolani model the controlling variable is bending moment $\mathrm{M}$.

To calibrate the numerical procedures and to provide data for the subsequent case study, two composite joints tested experimentally at the University of Coimbra [6] were selected and are illustrated in Figure 5a and Figure 5b.

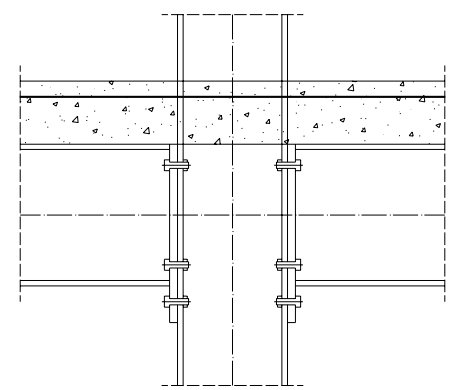

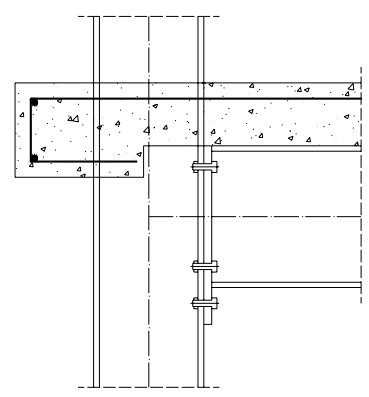

Fig. 5a: Experimental model of Joint E11 Fig. 5b: Experimental model of Joint E9.

Joint E9 represents an external node connection, while joint E11 represents an internal node connection. Using the parameters calibrated in the experimental study by Simões [3], Figures 6a, 6b and Figures 7a, 7b compare the experimental cyclic results for both joints with the numerical results using both models.

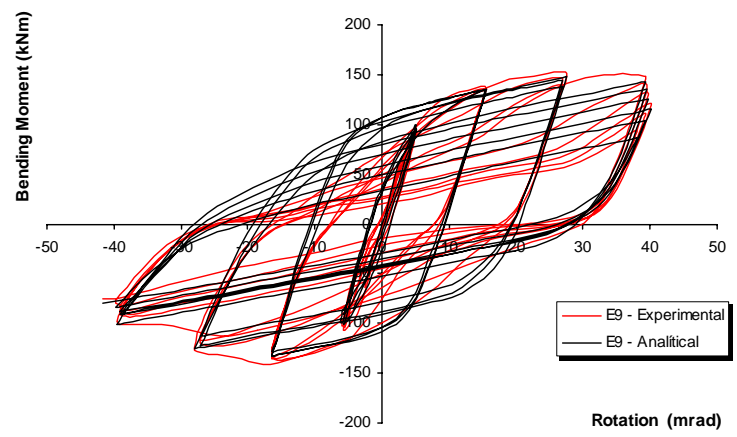

Fig. 6a: Hysteretic moment-rotation curves for Richard-Abbott model (E9).

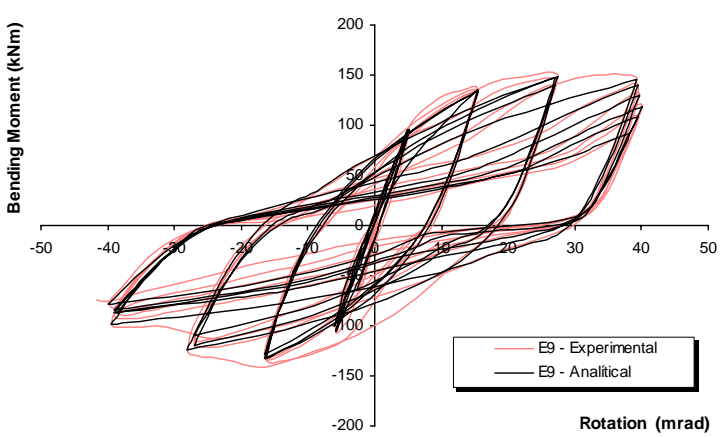

Fig.6b: Hysteretic moment-rotation curves for Modified Mazzolani model (E9).

It is noted that, for the levels of rotation that were reached experimentally, joint E9 exhibits significant slippage, while joint E11 hardly shows this pinching effect. Consequently, The Richard-Abbott model performs well in the later case, while it presents a significant deviation for joint E9. 


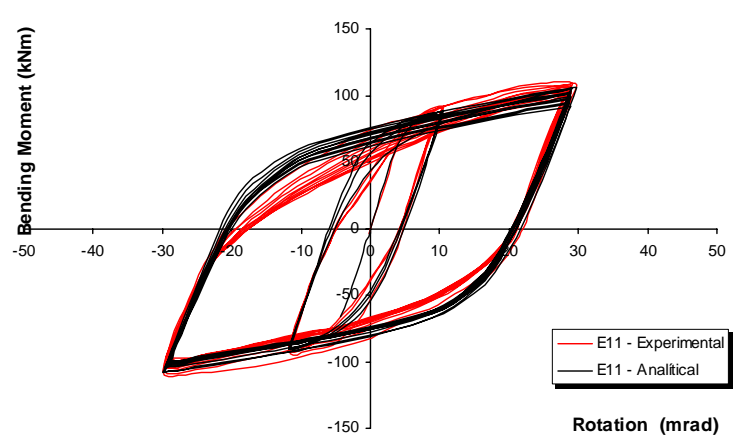

Fig. 7a: Hysteretic moment-rotation curves for Richard-Abbott model (E11)

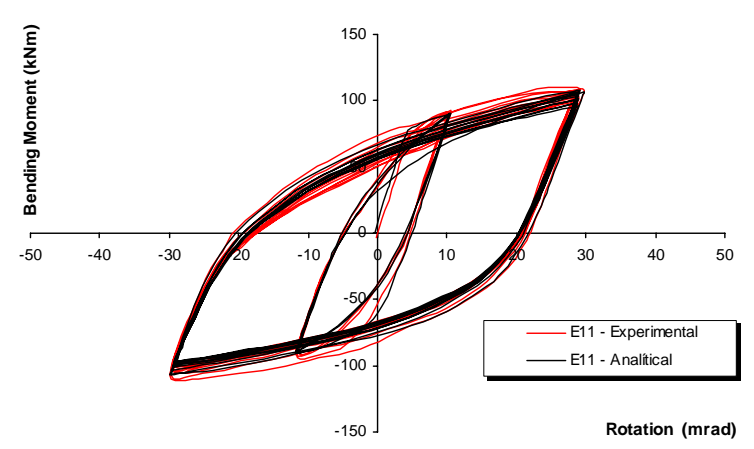

Fig.7b: Hysteretic moment-rotation curves for Modified Mazzolani model (E11).

\section{The case study}

\subsection{Generalities}

As briefly described in the introduction, a typical low-rise office building was selected. The architectural plan view of the ground floor being depicted in Figure 8.

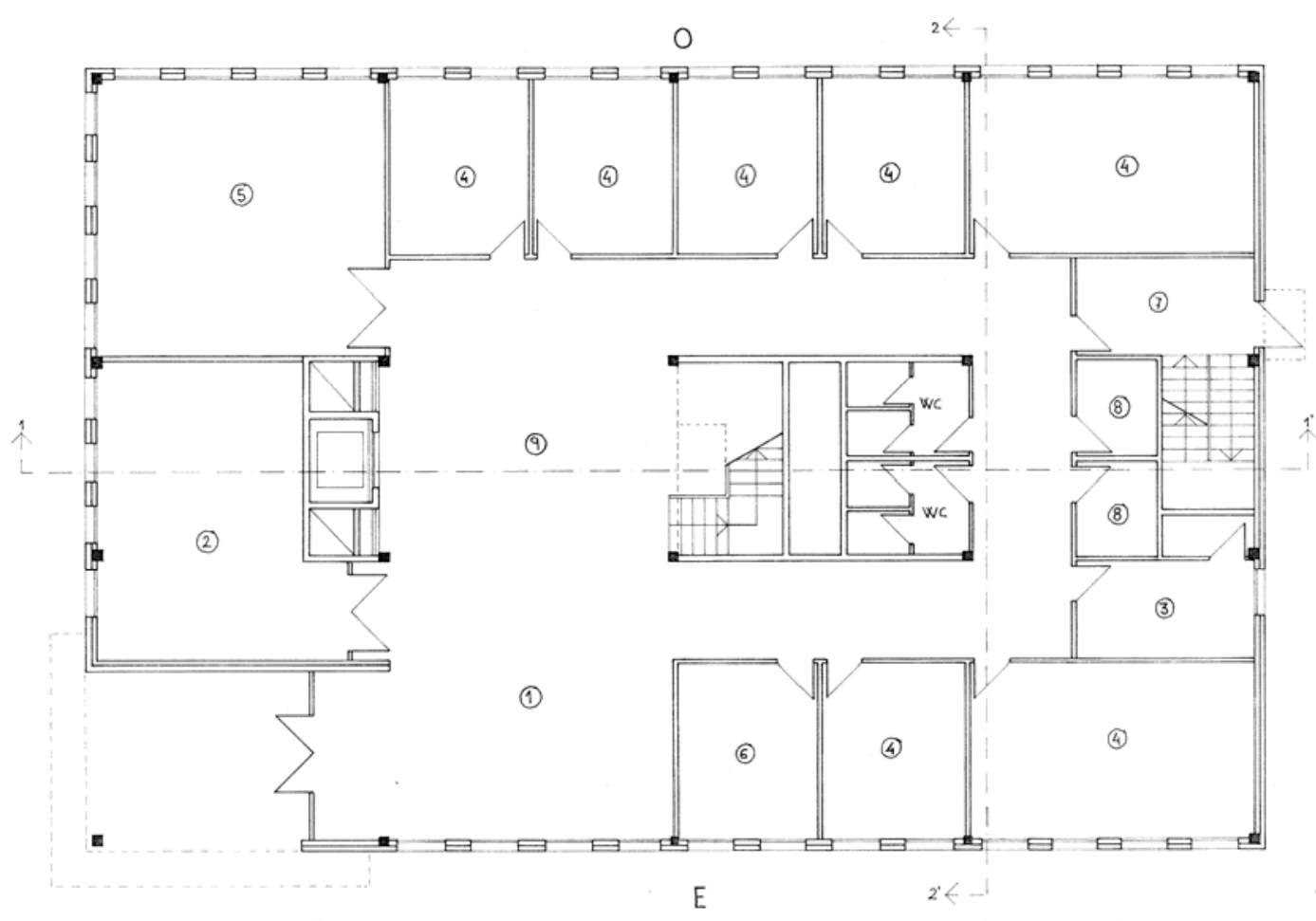

Figure 8: Architectural layout of the case study building. 
Basically, the structure consists of a two-storey building, with a inner service area (lifts, staircases, WC and storage and ducts), surrounded by a flexible office area, free from structural members.

The structural layout consists of an orthogonal grid with five alignments with 3 spans of 7.5-5-7.5m in the transverse direction and 4 alignments with 4 equal spans of $7.5 \mathrm{~m}$ in the longitudinal direction. The total height of the steel frames is $7 \mathrm{~m}$ (3.5 $\mathrm{m}$ in each floor).

The structure is composed of HEA 220 columns and composite beams supporting a concrete slab, illustrated in Figure 9.

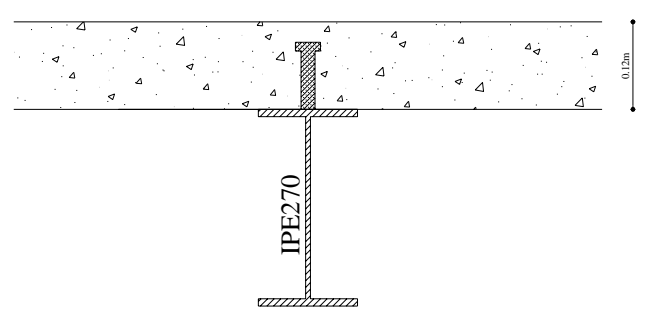

Figure 9: Composite cross section.

Gravity loading is described in Table 1 and comprises permanent and superimposed loading

Table 1: Gravity loading

\begin{tabular}{cc}
\hline \multicolumn{2}{c}{ Loads } \\
\hline Permanent load (self-weight, finishes, etc.) & $3.0 \mathrm{kN} / \mathrm{m}^{2}$ \\
\hline Variable load & $2.0 \mathrm{kN} / \mathrm{m}^{2}$ \\
\hline
\end{tabular}

\subsection{The reference frame and loading strategy}

Given the symmetry of the structure and to simplify the analysis, a major axis internal frame was selected, deemed to represent the structural response of the building. It is schematically represented in Figure 10.

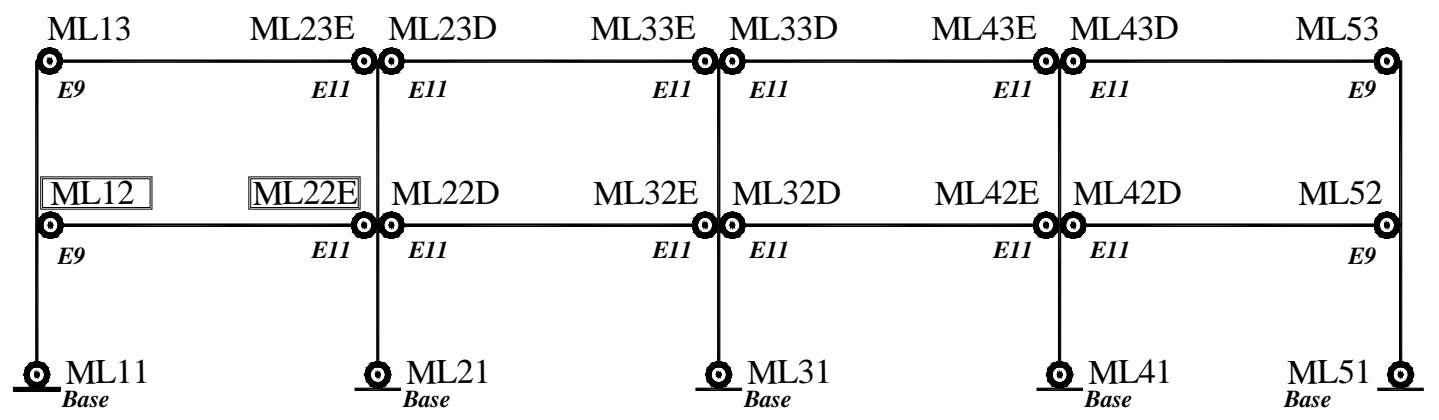

Figure 10: Reference frame. 
In Figure 10 MLxx denotes the structural node and E9 or E11 identify the chosen joint configuration, as described in section 2. Additionally, the column bases (denoted Base) were assumed with the same flexural stiffness and resistance as the connecting columns.

To loading strategies were adopted: (i) a single cyclic horizontal force applied at the second floor level, as shown in Figure 11a and, (ii) the same cyclic load, superimposed with the gravity loading described earlier, corresponding to a serviceability level, shown in Figure 11b.

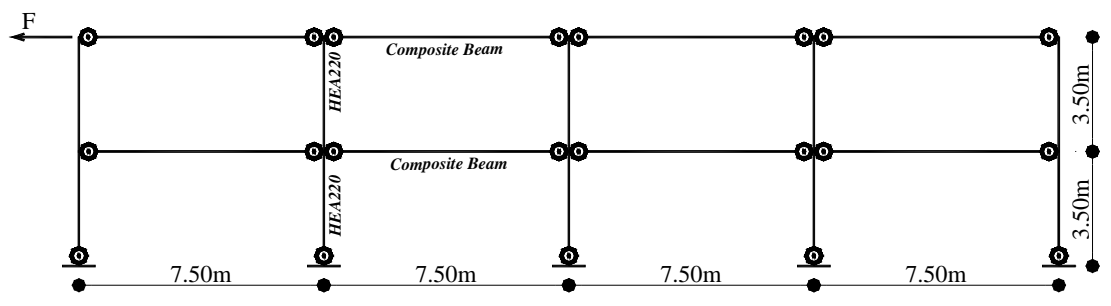

Figure 11a: Load case 1- single cyclic horizontal force.

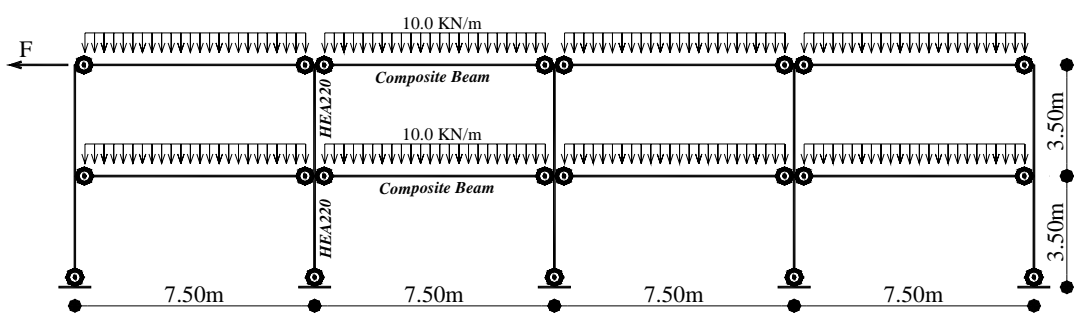

Figure 11b: Load case 2- single cyclic horizontal force, superimposed with gravity loading.

The cyclic load is fully characterized in Figure 12, follows the ECCS load

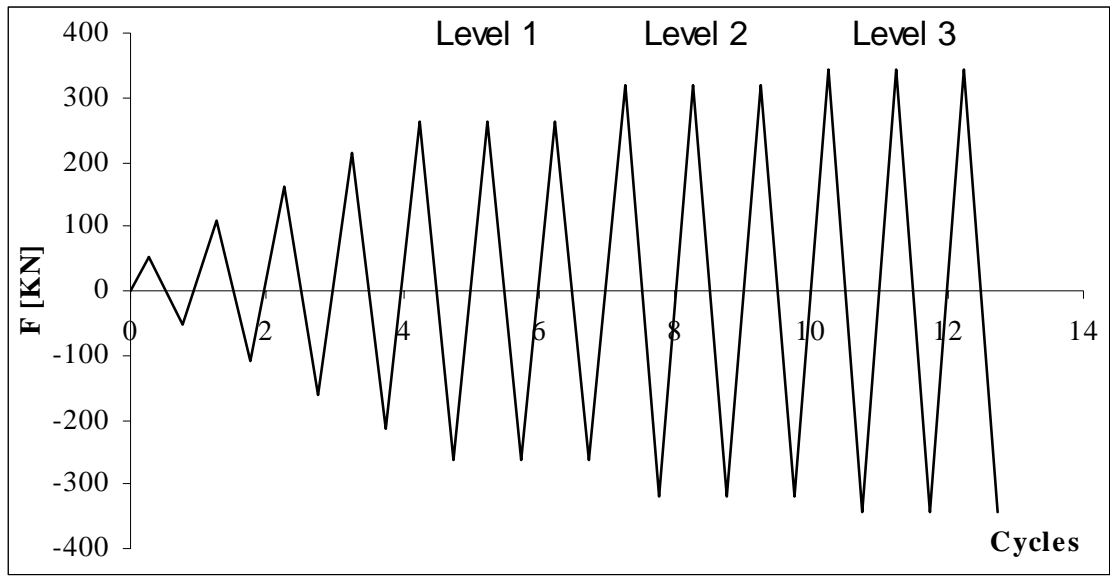

Figure 12: Characterization of cyclic load. 
application strategy [7] and was calibrated as follows: (i) firstly, four load cycles were applied with amplitudes $\pm 1 / 4 \times F_{Y}, \pm 2 / 4 \times F_{Y}, \pm 3 / 4 \times F_{Y}, \pm F_{Y}$, respectively, where $\mathrm{F}_{\mathrm{Y}}$ denotes the level of applied force that yields the critical joint (ML22E); (ii) secondly, three equal load cycles (Level 1) were applied to the structure such that rotation at joint ML22E reaches about 11 mrad; (iii) next, another three equal load cycles (Level 2) were imposed to the structure, leading to a joint rotation at joint ML22E of 30 mrad; (iv) finally, three more equal load cycles were applied to the structure, such that joint ML12 reaches 40 mrad. These force amplitudes and rotation levels were chosen to ensure that results at the selected joints can be directly compared with the experimental results and that slippage is attained at joint ML12.

The structural analysis was carried out using the finite element code Seismosoft [8], the joints being modelled using hysteretic bi-linear spring elements. The characterisation of the joints is shown in Figure 13:

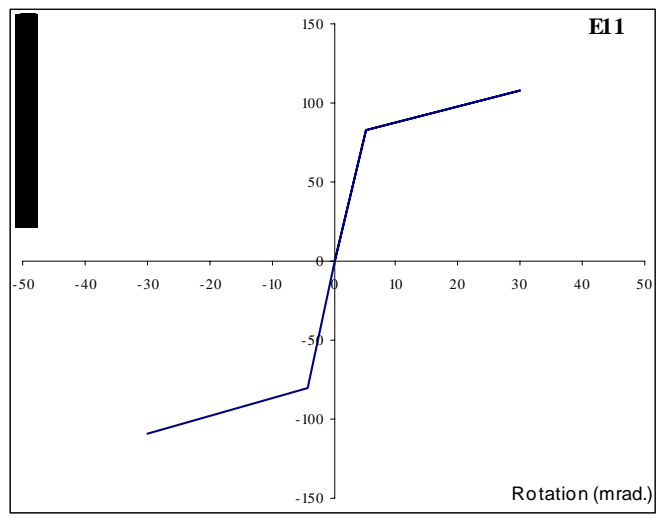

Fig.13a - Hysteretic bi-linear curve for joint E11.

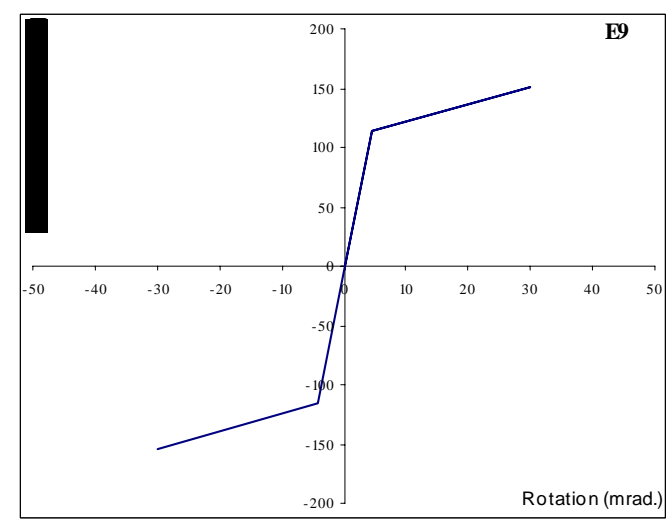

Fig.13b - Hysteretic bi-linear curve for joint E9.

Because these spring elements do not allow for degradation of the joint properties, this effect was assessed in a two-step procedure, later detailed in this paper.

\subsection{Results and discussion}

\subsubsection{Global results without degradation of joint properties}

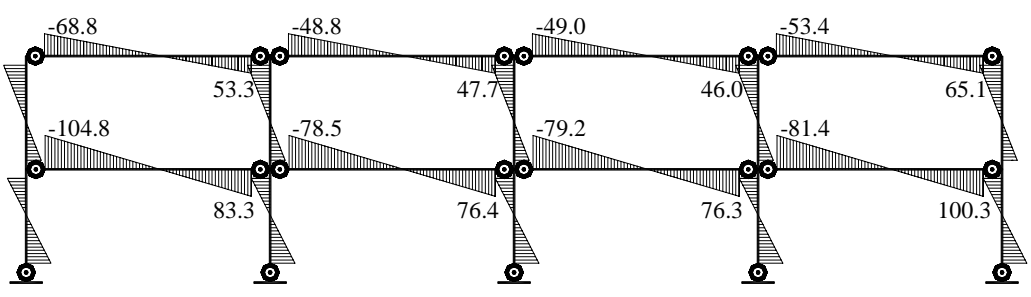

Fig.14 - Bending Moment diagrams for load level $\mathrm{F}_{\mathrm{Y}}$. 


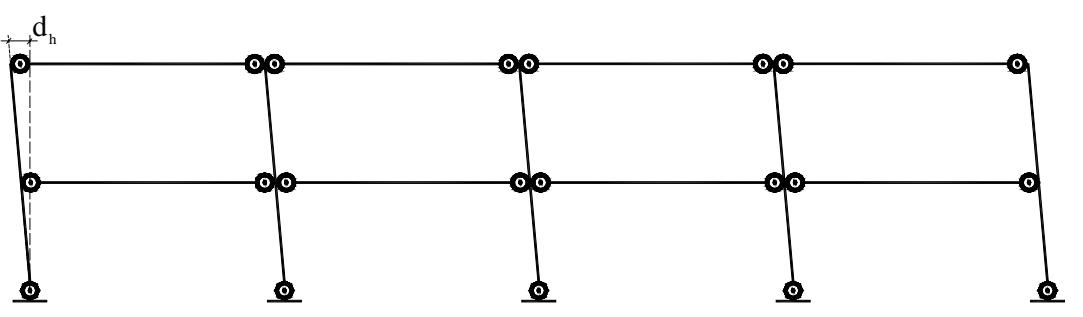

Fig.15 - Deformed structure for load level $\mathrm{F}_{\mathrm{Y}}$.

Starting with the first load case, horizontal cyclic force only, four distinct load levels were analysed: $F_{Y}$, L1, L2 and L3, already described earlier. Figures 14 and 15 illustrate the bending moment diagram and the deformed shape of the reference frame. Table 2 indicates the bending moments at the various connections for the four load levels, while Table 3 shows the corresponding horizontal displacements.

Table 2 - Bending moments for load case 1

\begin{tabular}{cccccccccc}
\hline Joint & $\begin{array}{c}\mathrm{F}_{\mathrm{Y}} \\
\text { KNm }\end{array}$ & $\begin{array}{c}\text { Level 1 } \\
\text { KNm }\end{array}$ & $\begin{array}{c}\text { Level 2 } \\
\text { KNm }\end{array}$ & $\begin{array}{c}\text { Level 3 } \\
\text { KNm }\end{array}$ & Joint & $\begin{array}{c}\mathrm{F}_{\mathrm{Y}} \\
\text { KNm }\end{array}$ & $\begin{array}{c}\text { Level 1 } \\
\text { KNm }\end{array}$ & $\begin{array}{c}\text { Level 2 } \\
\text { KNm }\end{array}$ & $\begin{array}{c}\text { Level 3 } \\
\text { KNm }\end{array}$ \\
\hline \hline ML12 & -104.8 & -119.4 & -144.8 & -161.6 & ML33E & 47.7 & 62.2 & 70.2 & 73.0 \\
\hline ML13 & -68.8 & -91.6 & -130.6 & -137.7 & ML33D & -49.0 & -64.3 & -72.8 & -76.6 \\
\hline ML22E & 83.4 & 88.1 & 104.2 & 115.2 & ML42E & 76.3 & 86.6 & 102.4 & 113.1 \\
\hline ML22D & -78.5 & -85.4 & -103.1 & -115.2 & ML42D & -81.4 & -86.7 & -104.7 & -117.0 \\
\hline ML23E & 53.3 & 68.3 & 79.7 & 83.4 & ML43E & 46.0 & 59.7 & 62.7 & 68.1 \\
\hline ML23D & -48.8 & -62.2 & -64.3 & -67.2 & ML43D & -53.4 & -70.0 & -81.0 & -82.0 \\
\hline ML32E & 76.4 & 86.7 & 102.5 & 113.2 & ML52 & 100.3 & 117.5 & 141.1 & 156.8 \\
\hline ML32D & -79.2 & -85.3 & -103.0 & -115.1 & ML53 & 65.1 & 87.3 & 127.9 & 136.2 \\
\hline
\end{tabular}

Table 3 - Horizontal displacements at the top level

\begin{tabular}{ccccc}
\hline Load Level & $\mathrm{F}_{\mathrm{Y}}$ & L1 & L2 & L3 \\
\hline \hline $\mathrm{d}_{\mathrm{h}}(\mathrm{mm})$ & -86.8 & -119.4 & -262.0 & -361.3 \\
\hline
\end{tabular}

Similar results for the second load case are shown in Figures 16 and 17 and Tables 4 and 5.

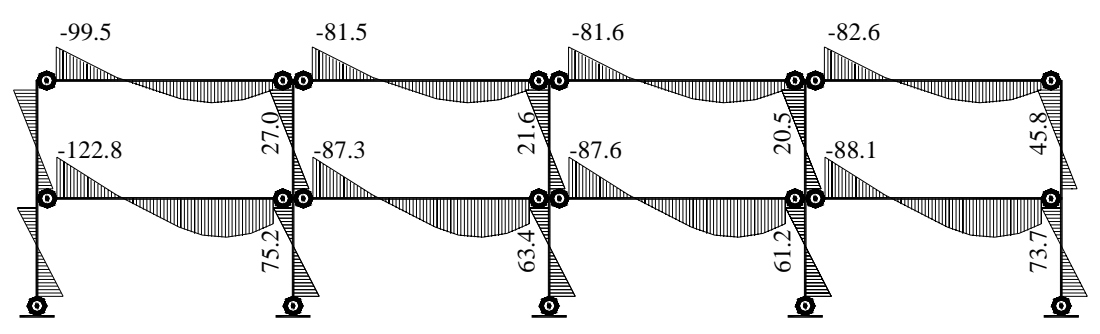

Figure 16 - Bending moment diagrams for load level $\mathrm{F}_{\mathrm{Y}}$. 


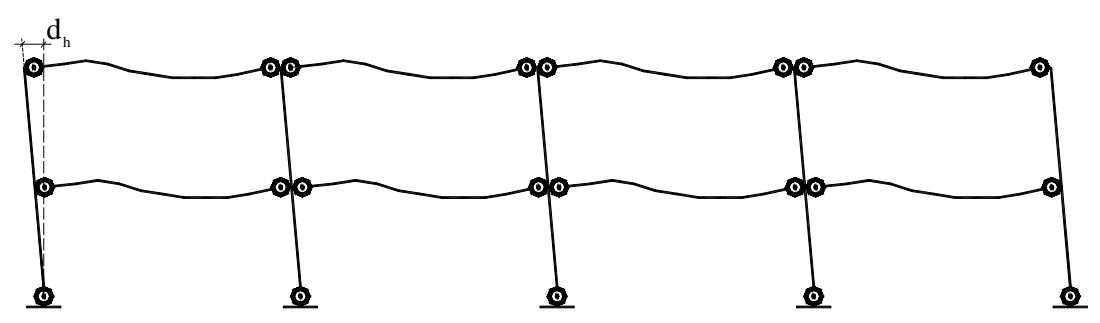

Figure 17 - Deformed structure for load level $\mathrm{F}_{\mathrm{Y}}$.

Table 4 - Bending moments for load case 2

\begin{tabular}{cccccccccc}
\hline Joint & $\begin{array}{c}\mathrm{F}_{\mathrm{Y}} \\
\text { KNm }\end{array}$ & $\begin{array}{c}\text { Level 1 } \\
\text { KNm }\end{array}$ & $\begin{array}{c}\text { Level 2 } \\
\text { KNm }\end{array}$ & $\begin{array}{c}\text { Level 3 } \\
\text { KNm }\end{array}$ & Joint & $\begin{array}{c}\mathrm{F}_{\mathrm{Y}} \\
\text { KNm }\end{array}$ & $\begin{array}{c}\text { Level 1 } \\
\text { KNm }\end{array}$ & $\begin{array}{c}\text { Level 2 } \\
\text { KNm }\end{array}$ & $\begin{array}{c}\text { Level 3 } \\
\text { KNm }\end{array}$ \\
\hline \hline ML12 & -122.8 & -129.9 & -169.4 & -197.6 & ML33E & 21.6 & 41.4 & 61.4 & 71.3 \\
\hline ML13 & -99.5 & -117.6 & -139.4 & -146.3 & ML33D & -81.6 & -85.0 & -86.6 & -86.7 \\
\hline ML22E & 75.2 & 84.6 & 110.2 & 127.5 & ML42E & 61.2 & 82.9 & 108.0 & 124.6 \\
\hline ML22D & -87.3 & -92.8 & -121.0 & -139.9 & ML42D & -88.1 & -93.9 & -122.6 & -141.6 \\
\hline ML23E & 27.0 & 49.2 & 68.6 & 77.9 & ML43E & 20.4 & 39.9 & 56.5 & 64.7 \\
\hline ML23D & -81.5 & -83.7 & -81.3 & -81.9 & ML43D & -82.6 & -86.3 & -90.9 & -92.3 \\
\hline ML32E & 63.4 & 83.0 & 108.2 & 125.0 & ML52 & 73.7 & 112.3 & 150.0 & 176.3 \\
\hline ML32D & -87.6 & -92.7 & -120.9 & -140.0 & ML53 & 45.8 & 69.7 & 132.8 & 140.6 \\
\hline
\end{tabular}

Table 5 - Horizontal displacements at the top level

\begin{tabular}{cccccc}
\hline Load Level & Gravity Load & $\mathrm{F}_{\mathrm{Y}}$ & Level 1 & Level 2 & Level 3 \\
\hline \hline $\mathrm{d}_{\mathrm{h}}(\mathrm{mm})$ & 0.12 & -97.7 & -131.5 & -362.2 & -529.0 \\
\hline
\end{tabular}

Comparing both loading cases, increased horizontal displacements are noted for the second case, together with increased negative moments.

\subsubsection{Joint behaviour}

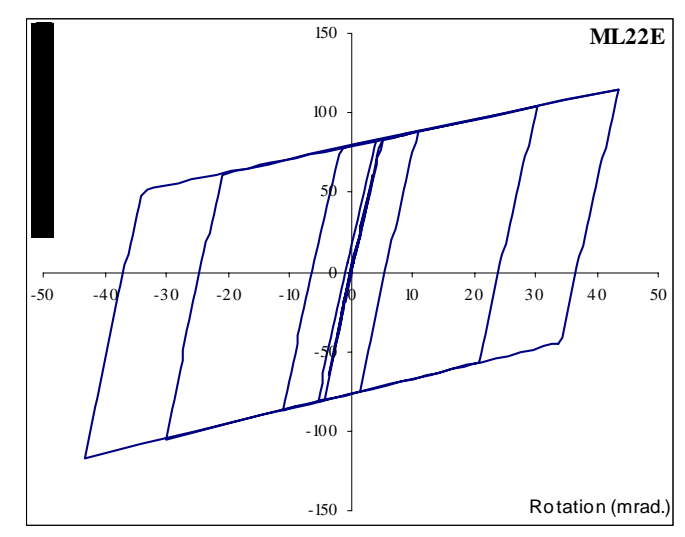

Figure.18a - Hysteretic moment-rotation curve for joint ML22E.

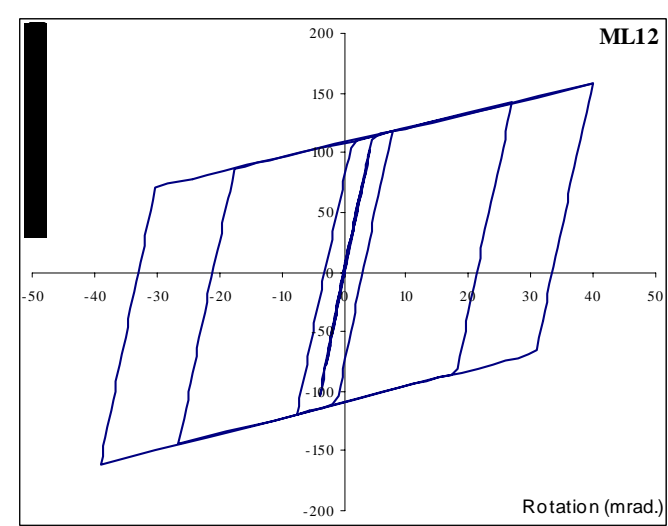

Figure18b - Hysteretic moment-rotation curve for joint ML12. 
Looking in more detail at the response of the critical connections (external and internal nodes), Figure 18 illustrates the hysteretic moment-rotation curves for both ML22E and ML12 joints, that, as already referred previously, do not exhibit neither strength and stiffness degradation nor slippage.

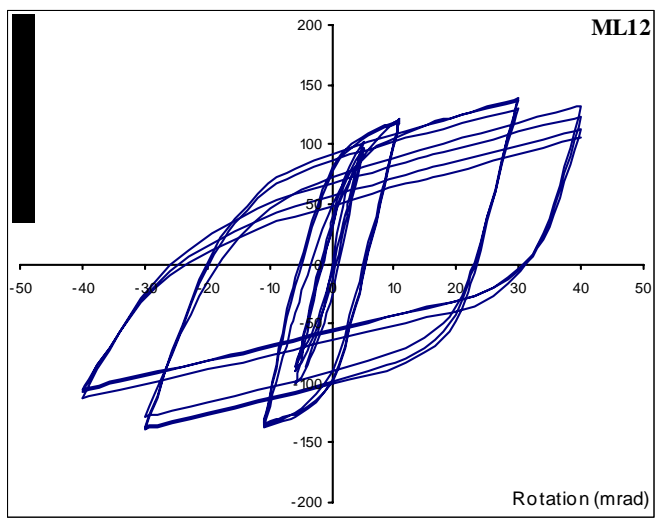

Fig.19a - Hysteretic moment-rotation curve for joint ML12-Richard-Abbott

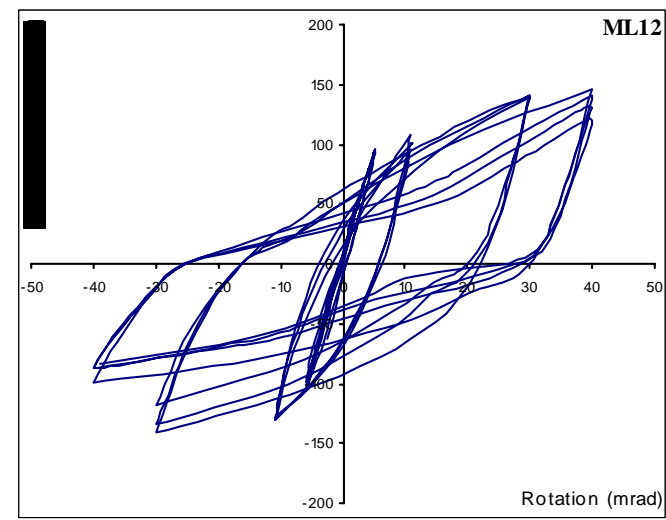

Fig.19b - Hysteretic moment-rotation curve for joint ML12- Mod. Mazzolani

Concentrating on joint ML12 (because of the availability of experimental results with slippage), running both numerical models (Richard-Abbott and Mazzolani models) for the rotation limits of Figure 18b it is obtained the results of Figure 19, also summarized in Table 6.

Table 6 - Rotations values and correspondent bending moment and stiffness, from ML12 connection.

\begin{tabular}{ccccc|ccccc}
\hline & \multicolumn{2}{c}{ Richard-Abbott } & \multicolumn{2}{c|}{ Mazzolani } & \multicolumn{3}{c}{ Richard-Abbott } & \multicolumn{2}{c}{ Mazzolani } \\
\hline $\begin{array}{c}\boldsymbol{\emptyset} \\
\mathbf{m r a d}\end{array}$ & $\begin{array}{c}\mathbf{M} \\
\mathbf{K N m}\end{array}$ & $\begin{array}{c}\mathbf{K} \\
\mathbf{K N m} / \mathbf{m r a d}\end{array}$ & $\begin{array}{c}\mathbf{M} \\
\mathbf{K N m}\end{array}$ & $\begin{array}{c}\mathbf{K} \\
\text { KNm/mrad }\end{array}$ & $\begin{array}{c}\boldsymbol{\emptyset} \\
\mathbf{m r a d}\end{array}$ & $\begin{array}{c}\mathbf{M} \\
\mathbf{K N m}\end{array}$ & $\begin{array}{c}\mathbf{K} \\
\text { KNm/mrad }\end{array}$ & $\begin{array}{c}\mathbf{M} \\
\mathbf{K N m}\end{array}$ & $\begin{array}{c}\mathbf{K} \\
\text { KNm/mrad }\end{array}$ \\
\hline-11 & -136.5 & 19.26 & -131.0 & 19.26 & 40 & 131.4 & 12.2 & 145.3 & 12.2 \\
\hline 30 & $\mathbf{1 3 8 . 7}$ & 22.14 & 138.6 & 22.14 & -40 & -113.5 & 19.2 & -99.5 & 19.2 \\
\hline-30 & $\mathbf{- 1 3 8 . 2}$ & 14.88 & $\mathbf{- 1 4 0 . 0}$ & 14.88 & 40 & 123.9 & 9.5 & 140.1 & 9.5 \\
\hline 30 & 136.3 & 20.70 & $\mathbf{1 4 1 . 3}$ & 20.70 & -40 & -105.1 & 18.4 & -87.1 & 18.4 \\
\hline-30 & -136.7 & 14.37 & -133.5 & 14.37 & 40 & 112.0 & 8.2 & 129.9 & 8.2 \\
\hline 30 & 129.9 & 19.47 & 141.0 & 19.47 & -40 & $\mathbf{- 1 0 6 . 0}$ & 18.3 & $\mathbf{- 8 7 . 7}$ & 18.3 \\
\hline-30 & -128.0 & 12.21 & -117.7 & 12.21 & 40 & $\mathbf{1 0 5 . 2}$ & 8.4 & $\mathbf{1 1 9 . 0}$ & 8.4 \\
\hline
\end{tabular}

It is worth noting that slippage only occurs for rotations above 30 mrad. In this case (modified Mazzolani model), 15\% and 35\% degradation of resistance are observed for the ascending and descending branches, respectively. Analogously, 60\% and $15 \%$ stiffness degradation is also noted for the ascending and descending branches, respectively.

\subsubsection{Comparative results considering equivalent joint degradation}

To simulate the results including slippage and degradation of joint properties, the bi- 
linear springs used in the global analysis were adjusted to reproduce the joint behaviour, as shown in Figure 20:

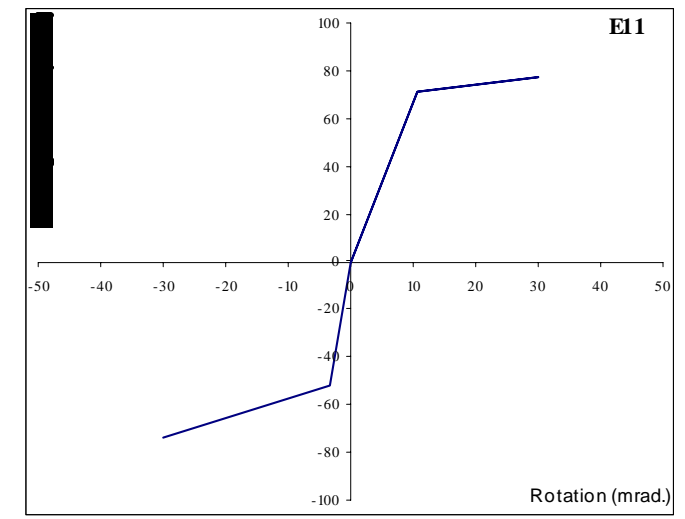

Fig.20a - Equivalent hysteretic bi-linear curve for joint E11.

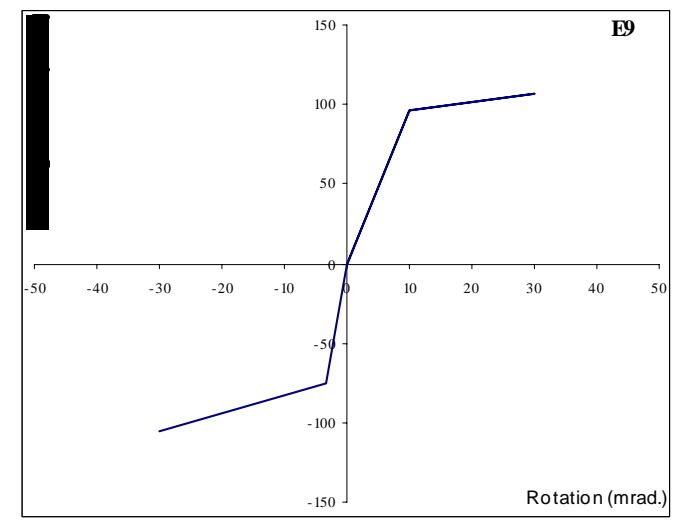

Fig.20a - Equivalent hysteretic bi-linear curve for joint E9.

To compare meaningful results, bending moments at joint rotations of $\pm 30 \mathrm{mrad}$ and $\pm 40 \mathrm{mrad}$ are presented in Tables 7 and 8 for negative and positive rotations, respectively. In table 7 a decrease of bending moment of approximately $20 \%$ is clearly observed, both for the external nodes and the internal nodes of the first floor. A redistribution of internal forces to the internal nodes of the second floor is also noted. Similar results are obtained for load case 2.

Table 7 - Comparative bending moments $(\mathrm{kNm})$ for negative rotations. Load case 1.

\begin{tabular}{cccccccc}
\hline Joint & $\begin{array}{c}\boldsymbol{\emptyset}=\mathbf{- 3 0} \\
\text { mrad }\end{array}$ & $\begin{array}{c}\boldsymbol{\emptyset}=\mathbf{- 4 0} \\
\text { mrad }\end{array}$ & $\mathbf{\%}$ & Joint & $\begin{array}{c}\boldsymbol{\emptyset}=\mathbf{- 3 0} \\
\text { mrad }\end{array}$ & $\begin{array}{c}\boldsymbol{\emptyset}=\mathbf{- 4 0} \\
\text { mrad }\end{array}$ & $\mathbf{\%}$ \\
\hline \hline ML12 & -144.8 & -113.6 & -21.5 & ML33E & 70.2 & 73.3 & +4.2 \\
\hline ML13 & -130.6 & -105.1 & -19.5 & ML33D & -72.8 & -66.2 & -9.1 \\
\hline ML22E & 104.2 & 80.6 & -22.6 & ML42E & 102.4 & 80.0 & -21.9 \\
\hline ML22D & -103.1 & -81.3 & -21.1 & ML42D & -104.7 & -82.4 & -21.3 \\
\hline ML23E & 79.7 & 73.9 & -7.3 & ML43E & 62.7 & 73.0 & +14.1 \\
\hline ML23D & -64.3 & 66.0 & +2.6 & ML43D & -81.0 & -66.8 & -17.5 \\
\hline ML32E & 102.5 & 80.0 & -22.0 & ML52 & 141.1 & 110.4 & -21.8 \\
\hline ML32D & -103.0 & -81.3 & -21.1 & ML53 & 127.9 & 105.9 & -17.2 \\
\hline
\end{tabular}

Table 8 - Comparative bending moments $(\mathrm{kNm})$ for positive rotations. Load case 1.

\begin{tabular}{|c|c|c|c|c|c|c|c|}
\hline Joint & $\begin{array}{l}\emptyset=30 \\
\text { mrad }\end{array}$ & $\begin{array}{c}\emptyset=40 \\
\text { mrad }\end{array}$ & $\%$ & Joint & $\begin{array}{l}\emptyset=30 \\
\text { mrad }\end{array}$ & $\begin{array}{c}\emptyset=40 \\
\text { mrad }\end{array}$ & $\%$ \\
\hline ML12 & 141.5 & 110.6 & -21.8 & ML33E & -73.0 & -66.2 & -9.3 \\
\hline ML13 & 128.6 & 106.1 & -17.5 & ML33D & 70.0 & 73.3 & +4.5 \\
\hline ML22E & -104.5 & -82.6 & -21.0 & ML42E & -103.0 & -81.3 & -21.1 \\
\hline ML22D & 102.5 & 80.0 & -22.0 & ML42D & 104.1 & 80.5 & -22.6 \\
\hline ML23E & -81.2 & -67.0 & -17.5 & ML43E & -62.5 & -65.9 & +5.2 \\
\hline ML23D & 62.7 & 73.1 & +14.2 & ML43D & 81.4 & 73.8 & -9.3 \\
\hline ML32E & -103.1 & -81.3 & -21.1 & ML52 & -144.4 & -113.3 & -21.5 \\
\hline ML32D & 102.5 & 80.0 & -22.0 & ML53 & -129.8 & -104.3 & -19.6 \\
\hline
\end{tabular}




\section{Conclusions}

Based on a case study, typical of a low-rise office building, the behaviour and influence of joint slippage and degradation on the cyclic response of steel frames was presented. Because of the unavailability of a joint element with degradation and slippage in the global analysis, an indirect approach was used, using an equivalent bi-linear spring.

Results highlighted variations of $20 \%$ in bending moments and significant redistributions of internal forces, thus stressing the importance of a correct assessment of this effect.

\section{Acknowledgements}

The use of the Seismosoft program is acknowledged.

\section{References}

[1] Richard, R. M. and Abbott, B. J. (1975) Versatile Elasto-Plastic Stress-Strain Formula. Journal of the Engineering Mechanics Division, ASCE, 101, EM4, 511-515.

[2] De Martino, A., Faella, C. and Mazzolani, F. M. (1984) Simulation of Beamto-Column Joint Behaviour under Cyclic Loads. Construzioni Metalliche, 6, 346-356.

[3] Simões, R., L. Simões da Silva, L. and Cruz P., "Behaviour of End-Plate Beam-to-Column Composite joints under cyclic Loading”, International Journal of Steel and Composite Structures, 1(3), 355-376 (2001).

[4] Mazzolani, F.M. (1988) Mathematical Model for Semi-Rigid Joints Under Cyclic Loads, in R. Bjorhovde et al. (eds.) Connections in Steel Structures: Behaviour, Strength and Design, Elsevier Applied Science Publishers, London, 112-120.

[5] Delphi 7, Borland Software Corporation (2002).

[6] Simões da Silva, L., Simões, R. and Cruz, P.J., "Experimental Behaviour of End-Plate Beam-to-Column Composite Joints under Monotonical Loading", Engineering Structures 23(11), 1383-1409 (2001).

[7] ECCS (1986) Recommended Testing Procedure for Assessing the Behaviour of Structural Steel Elements under Cyclic Loads - Nº45.

[8] SeismoStruct, "Computer program for static and dynamic nonlinear analysis of framed structures" [online]. Available from URL: http://www.seismosoft.com (2003) 